\title{
Statistical analysis of negative prices in European balancing markets
}

\author{
Tom Brijs ${ }^{\mathrm{a}, \mathrm{b},{ }^{*} \text {, Kristof De Vos }}{ }^{\mathrm{a}, \mathrm{b}}$, Cedric De Jonghe ${ }^{\mathrm{a}, \mathrm{b}}$, Ronnie Belmans ${ }^{\mathrm{a}, \mathrm{b}}$ \\ ${ }^{a}$ ELECTA, Department of Electrical Engineering, University of Leuven (KU Leuven), Kasteelpark Arenberg 10, 3001 Heverlee, Belgium \\ ${ }^{\mathrm{b}}$ EnergyVille, 3600 Genk, Belgium
}

\section{A R T I C L E I N F O}

\section{Article history:}

Received 19 April 2014

Accepted 24 January 2015

Available online 14 February 2015

\section{Keywords:}

Balancing market

Electricity prices

Market design

Negative prices

Renewable energy

\begin{abstract}
A B S T R A C T
The presence of renewable power generation technologies increases the need for system flexibility due to their variable nature. The increasing share of variable renewables in European power systems create a downward adequacy problem, which deals with the ability of power systems to cope with periods of excess generation. The occurrence of negative prices on Central Western European electricity markets confirms the relevance of this issue, which is referred to as "incompressibility of power systems" and is assessed as a barrier for further renewable power integration. The objective of this article is to identify the main drivers of negative price periods in European balancing markets, by means of both an empirical and regression analysis. Results confirm a positive relation with the scheduled generation of renewables and inflexible base load, as well as a negative relation with the scheduled system load. Furthermore, the occurrence of negative prices is related to the positive and negative forecast error of renewable generation and demand, respectively. It is concluded that negative balancing market prices provide a market signal for investments in flexibility sources such as flexible generation, demand response, electricity storage, and interconnector capacity.
\end{abstract}

๑) 2015 Elsevier Ltd. All rights reserved.

\section{Introduction}

Renewable energy sources for electricity (RES-E) in the European Union have benefited from support schemes for many years, resulting in a gradual increase of their installed capacity. Annual installations of wind power and photovoltaic (PV) have increased over the past decennia, resulting in a total installed capacity of respectively $101.6 \mathrm{GW}$ and $67.5 \mathrm{GW}$ at the end of 2012 for the EU-28 accompanied by Norway and Switzerland [1]. Table 1 represents national statistics of Central Western European countries in terms of the cumulative installed capacities and energy of wind and PV at the end of 2012. Germany is clearly leading the way, covering $13.6 \%$ of its electricity consumption with wind and PV. When compared to the minimum demand, this may already result in instantaneous renewable generation levels that exceed the demand. Table 1 shows that Belgium, the Netherlands, and France face lower average and maximum penetration levels, but trajectories show that they are also rapidly increasing their renewable generation mix [2]. In view of the European policy goals towards 2020 and

\footnotetext{
* Corresponding author. ELECTA, Department of Electrical Engineering, University of Leuven (KU Leuven), Kasteelpark Arenberg 10, 3001 Heverlee, Belgium. Tel.: +32485826161.

E-mail address: tom.brijs@esat.kuleuven.be (T. Brijs).
}

2030, this growth is expected to maintain, gradually increasing the impact on system and market operation.

Flexibility in power systems indicates the ability to provide upward and downward power adjustments on different time scales to maintain the balance between generation and consumption. The presence of renewable power generation technologies, particularly wind and PV, increases the need for this flexibility, due to the variability of their power output $[3,4]$. This variability may refer to both output variations and prediction errors [5]. On the one hand, expected output variations are generally covered by flexible conventional power plants, which are scheduled to balance these output variations. Consequently, these generating units are to be characterized by the flexibility to allow certain output variations, which can be scheduled on day-ahead or intra-day basis. On the other hand, unpredicted renewable power variations are to be compensated for in real-time. System flexibility is needed from power plants which can deviate from their scheduled output profile. In contrast to scheduled variations, prediction errors require capabilities which allow output variation close to real-time [6,7].

Historically, system operators, regulators and policy makers were mainly concerned about upward adequacy, which is the ability of power systems to meet peak demand and avoid load shedding or black-outs $[2,8]$. This topic remains relevant today, as stagnating investments in conventional generation in combination 
Table 1

Installed capacity [GW] and annual electricity generation [TWh] of wind and PV at the end of 2012 [1].

\begin{tabular}{|c|c|c|c|c|c|c|c|c|}
\hline & \multicolumn{4}{|c|}{ Wind } & \multicolumn{4}{|l|}{ PV } \\
\hline & GW & TWh & $\begin{array}{l}\text { Mean }^{\mathrm{a}} \\
{[\%]}\end{array}$ & $\begin{array}{l}\operatorname{Max}^{\mathrm{b}} \\
{[\%]}\end{array}$ & GW & TWh & $\begin{array}{l}\text { Mean }^{a} \\
{[\%]}\end{array}$ & $\begin{array}{l}\operatorname{Max}^{\mathrm{b}} \\
{[\%]}\end{array}$ \\
\hline Belgium & 1.3 & 2.3 & 2.70 & 21.00 & 2.5 & 1.6 & 1.90 & 40.30 \\
\hline Germany & 30.9 & 46.0 & 8.50 & 96.30 & 32.7 & 27.6 & 5.10 & 101.90 \\
\hline The Netherlands & 2.3 & 5.5 & 4.70 & 29.50 & 0.1 & n.a. & n.a. & 1.30 \\
\hline France & 7.5 & 14.9 & 3.00 & 24.40 & 3.4 & 3.9 & 0.80 & 11.00 \\
\hline
\end{tabular}

a Mean penetration: annual electricity generation relative to total electricity consumption.

b Max penetration: installed capacity relative to minimum consumption levels.

with increasing shares of variable renewable generation lead to an increased risk for periodical shortages [9]. However, currently attention rises for the issue of downward adequacy raising the question if the current power system is able to cope with periods of excess generation. Recent observations have shown that these events are caused by inflexibilities resulting from renewable generation with low marginal prices, generation support mechanisms, and priority dispatch, as well as conventional generation technologies bound by technical ramping constraints such as nuclear power, or power plants bound by must-run conditions following operational reserve requirements. This is particularly challenging in a system where an inelastic demand has to meet supply in realtime, in the presence of only limited storage capacity.

This issue is referred to as the "incompressibility of power systems" and is recently observed in different European electricity markets such as Belgium, Germany, France and the Netherlands, with hours showing negative electricity prices, as well on dayahead, intra-day and real-time balancing markets [10,11]. These negative prices represent the scarcity of downward flexibility, and therefore the difficulty of the system to cope with periods of excess generation. A better understanding of this phenomenon is thus a crucial element in adapting power systems to renewable generation as they induce market signals towards additional flexibility.

Negative prices in the context of forward and day-ahead markets have already been described extensively in the literature [12-21]. In contrast, this article focuses on the balancing market which seems to be more sensitive to price volatility due to its realtime nature. This market deals with the real-time deviations of scheduled market positions and is subject to stringent technical constraints imposed by generating units. Meanwhile, it is particularly challenged by the forecast errors of the increasing shares of wind and PV in electricity generation.

The objective of this article is to identify parameters which drive these negative prices on the real-time balancing market, by means of an empirical and regression analysis. The analysis of negative imbalance price drivers contributes to a better understanding of the need and availability of real-time downward flexibility, which will become more important with a higher share of RES in the generation mix.

Section 2 extends the background of this article. First, it analyzes the functioning of balancing markets while focusing on the Belgian case, taken as a representative example for the EU-28. Furthermore, a comparison is made with the neighboring Dutch, German, and French markets due to their interactions with the Belgian system. Second, relevant negative price drivers are identified according to an extensive literature review. Section 3 discusses the used data and applied empirical and regression methods. Section 4 provides the results of the executed empirical analysis of negative prices in the Belgian balancing market while identifying potential impact factors which induce negative imbalance prices. In addition, a regression analysis is conducted identifying significant independent variables with regard to imbalance prices. Finally, Section 5 provides a discussion, while Section 6 states the conclusions of this article.

\section{Theoretical discussion}

\subsection{Balancing market}

\subsubsection{Functioning}

The Transmission System Operator (TSO) operates on both the procurement and the settlement side of the balancing market. On the one hand, the TSO calculates the total system imbalance resulting from the imbalances of BRPs (Balance Responsible Parties), and compensates this system imbalance by activating reserve capacity provided by BSPs (Balance Service Providers). On the other hand, it settles imbalances with BRPs by applying an imbalance price. While long-term forward, day-ahead and intraday markets are based on forecasts, balancing markets use realtime information available after the previous markets closed regarding the need for and value of flexibility [22,23]. The reservation and activation of reserve capacity is thus referred to as the procurement side of the balancing market, and providers of reserve capacity are remunerated for their capacity and activation. Reservation costs are settled in the transmission tariffs and activation costs are transferred to the responsible market players by means of the imbalance settlement mechanism [24].

Unforeseen events (e.g. unplanned power unit outages or unexpected demand variations) between gate closure and real-time are thus dealt with on the balancing market. Today, with the increasing penetration of variable RES, prediction errors also result in an additional demand for balancing actions. On the procurement side the TSO contracts reserve capacity which is, today, mainly procured from conventional power units, and can be quickly activated in real-time to cover system imbalances. Usually, a minimum amount of reserve capacity is required to be contracted through long-term contracts by the regulator in order to obtain a minimum guaranteed reserve capacity. Next to the contracted reserves, capacity can be procured day-ahead. This results in a merit-order representing the activation cost of reserve capacity [7,25]. Remunerating BSPs can either be by pay-as-cleared pricing or by pay-asbid pricing. The former indicates that all units are remunerated at the marginal price of the system, which is the cost of activating one more unit of energy and is thus given by the least expensive reserve capacity that would have to be activated next [26]. The latter indicates that units are paid at their nominated price for the quantity activated by the TSO, which means that each generating unit receives a different compensation as different technologies bid at different prices in order to account for their costs [27].

A key characteristic of the settlement side of balancing markets is the calculation of imbalance prices. Two types of imbalance price mechanisms can be identified: a single-pricing scheme and a dualpricing scheme. A single-pricing scheme includes an imbalance price reflecting the marginal activation price of reserves, meaning that a uniform imbalance price is applied for BRPs facing positive and negative imbalances in real-time. A dual-pricing scheme includes a different price for BRPS facing positive and negative imbalances. When aggravating the system imbalance, the imbalance price is calculated based on the average activation costs of reserve capacity. When resolving the system imbalance, the imbalance price is usually based on day-ahead prices [22,23]. In addition, a difference also exists between marginal and average pricing. They are based on either the price of the marginally accepted reserve capacity bid (marginal pricing) or the average price of all accepted 


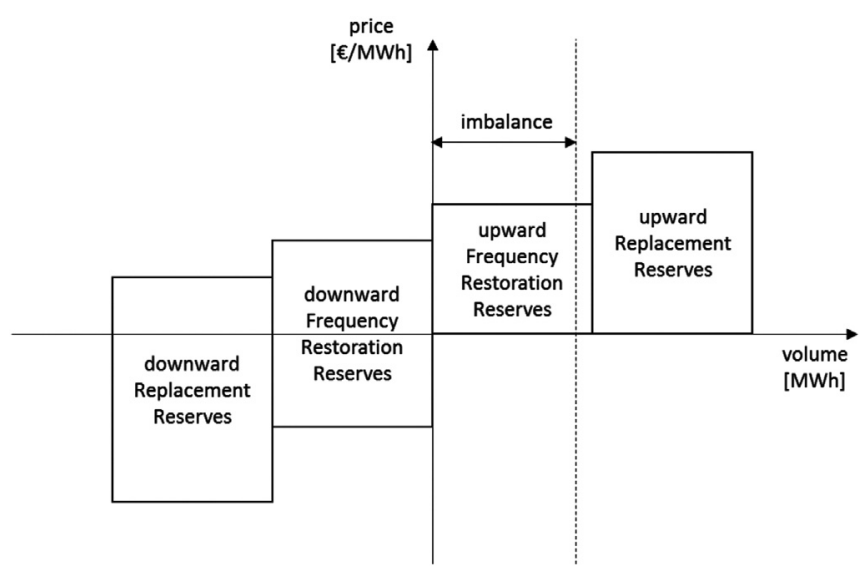

Fig. 1. Merit order for activating reserve capacity according to ENTSO-E.

reserve capacity bids (average pricing), depending on how BSPs are remunerated (pay-as-cleared versus pay-as-bid) [28,29].

In case of a negative system imbalance the TSO activates upward reserves, which results in a positive price and the TSO pays the BSP (Fig. 1, right). Reserve capacity is categorized in different categories: Frequency Containment Reserves (FCR), Frequency Restoration Reserves (FRR), and Replacement Reserves (RR). FCR is not further discussed since it is only activated in order to stabilize the frequency after deviations. First upward fast-response FRR including contracted and free bids from power units, and bids from interruptible demand can be activated. Second, the slow-response RR contain contracted and free bids from power units, and possibly a non-guaranteed emergency capacity from other TSOs [30,31].

In case of a positive system imbalance the TSO activates downward reserves, which can result in both positive and negative prices and thus the BSP pays the TSO or the TSO pays the BSP (Fig. 1, left). Downward reserves are provided by fast-response FRR including contracted and free bids from power units, and slowresponse RR containing free bids and possibly downward emergency capacity from neighboring TSOs. These downward reserves actually represent generators willing to lower their output, and since their energy is already sold in the forward market, they are usually willing to pay the TSO an amount which represents their saved operating costs. The TSO compensates the BRP having an excess supply by that (relatively small) amount. However, when facing scarcity, downward flexibility providers may bid positive activation prices, i.e. being paid for the service, leading to negative imbalance prices. In this case the BRPs facing a positive imbalance have to compensate the TSO instead of being paid for their excess supply $[30,31]$.

\subsubsection{The Belgian balancing market}

In Belgium, a single-pricing scheme is applied, in which the imbalance price reflects the marginal procurement price of reserves. Thus the 'same' imbalance price is applied for short and long positions ${ }^{1}$ after gate closure. However, this price is not always the same for long and short positions, as the Belgian imbalance prices must provide an incentive to BRPs to maintain balance in their portfolio. Therefore, when facing a large system imbalance, an additional incentivizing component is applied to 'punish' the BRPs contributing to the system imbalance. Balancing prices are calculated every $15 \mathrm{~min}$. Since October 2013 the Belgian system

\footnotetext{
${ }^{1}$ BRPs facing a negative imbalance hold a short position, BRPs facing a positive imbalance hold a long position.
}

imbalance is netted with other control zones by means of the International Grid Cooperation and Control (IGCC), which was initially designed for a better cooperation by the German TSOs (GCC). GCC covers four modules, which have all been implemented in Germany. IGCC currently only includes module one, which avoids counteracting activation of balancing resources through controlled and targeted real-time imbalance exchange between control areas. Elia is connected indirectly to Germany via the Dutch TSO 'TenneT'. Table 2 briefly compares some important characteristics of the Belgian [25,31], German [32,33], Dutch [34,35], and French [36,37] balancing markets.

\subsection{Negative electricity price drivers}

The main contribution of this article is the focus on the balancing market and the statistical analysis of the considered explanatory variables. The conclusions of the existing studies focusing on forward and day-ahead markets are discussed in this section as they provide insight in relevant explanatory variables.

Economic theory imposes that low demand together with a high supply at nearly-zero marginal cost results in lower market prices. In addition, literature shows that the simultaneous occurrence of high renewables generation and low system demand results in relatively expensive downward flexibility [12,13,16-18,20,21]. Even less flexibility is available when more base load units are online, due to stringent operational constraints (i.e. start-up costs, limited ramping rates, and long minimum up and downtimes) $[12,14,16,19]$. Finally, tight downward flexibility can also occur when the units that are online cannot shut down because they are contracted to provide reserve capacity $[11,14,19]$. Incompressibility can be defined as the lack of downward system flexibility [11], which may occur when there is a combination of a relatively low system load (i.e. usually during the weekend, night, or summer) and high nonflexible generation (i.e. wind, PV, inflexible base load), as this creates a generation surplus. Activation of scarce downward flexibility may result in negative prices.

The exact impact of variable RES generation on the activation of reserve capacity depends on a wide set of parameters [23]. First of all, the impact depends on the accuracy of forecast systems. Although the accuracy of wind and PV forecast systems steadily increases, forecast errors are expected to keep occurring [38]. Secondly, it strongly depends on the geographical spread and location of RES capacity, as renewable power output varies over time and location, and a geographically balanced portfolio may result in the smoothing of the variations and RES output forecast errors $[23,39]$. Thirdly, the impact depends on its correlation with other system imbalance drivers such as demand variability and unplanned power plant outages [12]. Although the exact impact of more renewables generation on the system imbalance depends on multiple factors, large-scale RES deployment is expected to increase the balancing needs of power systems [40,41].

In the meantime, conventional power, being the largest provider of balancing services, is gradually being replaced by renewable power generation. This results in a tight balancing market, facing an

Table 2

Characteristics of Central Western European balancing markets.

\begin{tabular}{|c|c|c|c|c|c|}
\hline & $\begin{array}{l}\text { Settlement } \\
\text { period }\end{array}$ & $\begin{array}{l}\text { Single/dual } \\
\text { pricing }\end{array}$ & $\begin{array}{l}\text { Marginal/ } \\
\text { average } \\
\text { pricing }\end{array}$ & $\begin{array}{l}\text { Incentivizing } \\
\text { component }\end{array}$ & $\begin{array}{l}\text { IGCC } \\
\text { participation }\end{array}$ \\
\hline Belgium & $15 \mathrm{~min}$ & Single & Marginal & Yes & Yes \\
\hline Germany & $15 \mathrm{~min}$ & Single & Average & Yes & Yes \\
\hline The Netherlands & $15 \mathrm{~min}$ & Single & Marginal & Yes & Yes \\
\hline France & $30 \mathrm{~min}$ & Dual & Average & No & No \\
\hline
\end{tabular}


increasing demand and decreasing supply for balancing services, and may lead to the occurrence of periods experiencing negative imbalance prices. The occurrence of negative prices on the balancing market can be seen as a market signal which represents a relative scarcity of cheap downward flexibility when facing positive system imbalances.

Finally, a relevant factor in analyzing the phenomena of negative prices is the fact that curtailment possibilities for RES-E generation are currently restricted [42]. This means that it is generally not encouraged or allowed to restrict wind or PV power generation, while conventional energy generation units are still online [43]. However, curtailment of renewable power generation in hours with an excess supply might serve as an incentive for investors to locate new renewable power units in locations with little risk of curtailment, and thereby geographically spreading renewable power generation units and its resulting output variations [42].

\section{Material and methods}

This section describes the methods used to evaluate recent imbalance prices for the Belgian control zone. A dataset of one year (1st of December 2012 - 30th of November 2013), published by the Belgian TSO [44], is empirically analyzed in Section 4.1. As the settlement of the balancing market prices is done on a quarterhourly period, the entire dataset consists of 35,040 entries. The relative frequency of negative imbalance prices is discussed, together with some basic statistics comparison with the four neighboring balancing markets. The data used to construct the accompanying Tables and Figures is publicly available at the websites of the Belgian, Dutch, German, and French TSOs [33,44-46]. The relation between the occurrence of negative imbalance prices and the selected drivers is analyzed by means of a statistical analysis. The selected drivers are chosen based on the conclusions of the literature review (Section 2.2).

The regression analysis, which is discussed in Section 4.2, uses the same dataset based on explanatory variables identified in the empirical analysis. These variables are the independent variables, which will all be tested for their significance and impact on the Belgian imbalance price, i.e. the dependent variable. The executed regression analysis shows the presence of a positive or negative relation between the independent variables and the dependent variable, as well as the percentage of the variance in the imbalance price that is explained by each independent variable. The significance of the tested independent variables is identified on the basis of a correlation analysis on each of the independent variables with the dependent variable [47].

After analyzing the regression models with SPSS, a software package used for statistical analysis, it is concluded that all necessary conditions to analyze the specified dataset by a linear regression analysis are met $[48,49]$. Important to note is that this statistical software calculates the probability that the tested variable is insignificant. A significance value lower than or equal to 0.01 means that the probability that the hypothesis is correct is lower than or equal to $1 \%$. In other words, the hypothesis can be rejected with a confidence level of $99 \%$ or more, meaning that the independent variable is significant with regard to the dependent variable with at least $99 \%$ certainty.

\section{Results}

\subsection{Imbalance price observations: empirical investigation}

When studying time series of the Belgian imbalance prices, it can be noted that negative prices are recorded in $6.78 \%$ of the time, while minima are registered at $-313.38 € / \mathrm{MWh}$. These values are compared to the neighboring German, French, and Dutch balancing markets (Table 3). Germany has the highest occurrence rate of negative prices (21.08\%), the Netherlands holds more or less the same rate as Belgium (6.73\%), and in France negative prices only occurred in less than $0.5 \%$ of the time (which is attributed to the imbalance price calculation method).

According to Section 2.2, potential drivers for the occurrence of negative prices are (i) inflexible base load units, (ii) RES power injections, and (iii) system load. In addition, as stated before renewable power generation technologies increase the need for flexibility due to their large variability, consisting of both expected output variations and forecast errors. Therefore the following paragraphs first discuss the observed relation between expected output variations in renewable power generation and system load (which are dealt with on the day-ahead market), and the occurrence of negative imbalance prices. Second, the observed relation between the renewables power forecast error and load forecast error (which are dealt with on the real-time balancing market), and the occurrence of negative imbalance prices is discussed.

The upper four graphs of Fig. 2 display the observed relation between the occurrence of negative prices (shown on the vertical axis on the left hand side) and the predicted hourly average power of wind and PV, and hourly average predicted load and net load. In addition, the probability of occurrence of the specified predicted value bins is shown on the right hand side. The predicted net load in this article is defined as the remaining load which has to be covered by flexible base load, mid load, and peak load power plants. Therefore it is calculated by subtracting the inflexible base load generation, i.e. the nuclear power generation for Belgium, and the renewables generation, from the forecasted load. For the occurrence of negative prices there seems to be a positive relation with the forecasted wind and PV power generation, and a negative relation with the forecasted load and net load. This relation is illustrated by the dark gray lines (left axis), as they represent the probability of an imbalance price to be negative when we find ourselves in that specified independent variable bin. In addition, the graphs in Fig. 2 also display light gray columns (right axis), representing the probability of being in the specified bin. For example, when looking at the day-ahead forecasted load it can be noted that the lower the load, the higher the probability of an imbalance price being negative, as the left axis for example states that the probability is $18 \%$ for day-ahead forecasted loads less than $7000 \mathrm{MW}$ in contrast to only $2 \%$ for loads more than $11,000 \mathrm{MW}$. In addition, the probability of being in a lower load bin is generally lower than being in a higher load bin, as the right axis for example states that the probability is $7 \%$ for day-ahead forecasted loads less than $7000 \mathrm{MW}$ in contrast to $10 \%$ for loads more than $11,000 \mathrm{MW}$.

The lower four graphs of Fig. 2 show the observed characteristics of the occurrence of negative imbalance prices (shown on the vertical axis on the left hand side) with regard to forecast error of wind, PV, load, and net load. These forecast errors are calculated by taking the difference between the real-time observed value and the day-ahead forecasted value, thus a positive forecast error means that the real-time value is higher than forecasted, and vice versa. The net load forecast error is calculated as the aggregated forecast

Table 3

Relative frequency of negative imbalance prices and basic statistics of four European balancing markets.

\begin{tabular}{lclrc}
\hline & $\begin{array}{c}\text { Negative } \\
\text { prices [\%] }\end{array}$ & $\begin{array}{l}\text { Mean price } \\
{[€ / \mathrm{MWh}]}\end{array}$ & $\begin{array}{l}\text { Min. price } \\
{[€ / \mathrm{MWh}]}\end{array}$ & $\begin{array}{l}\text { Max. price } \\
{[€ / \mathrm{MWh}]}\end{array}$ \\
\hline Belgium & 6.78 & 49.96 & -313.38 & 1488.20 \\
Germany & 21.08 & 34.19 & -2498.40 & 1608.20 \\
The Netherlands & 6.73 & 49.94 & -450.66 & 600.00 \\
France & 0.42 & 42.73 & -200.00 & 283.17 \\
\hline
\end{tabular}




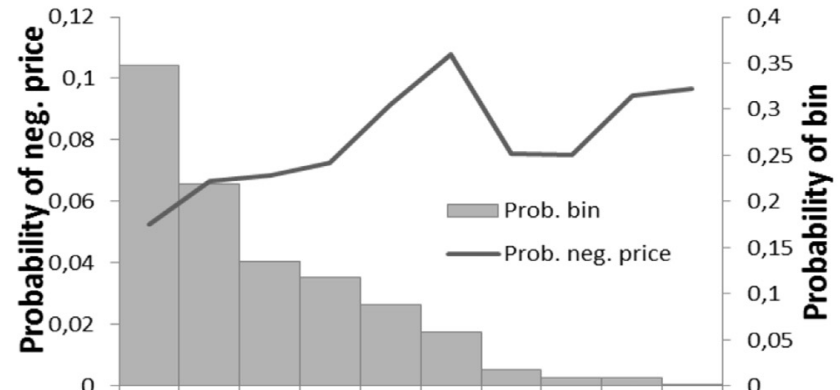

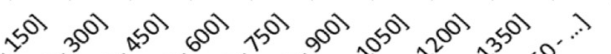

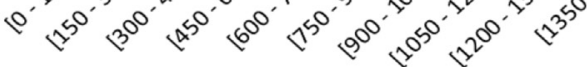

DA Forecast Wind Power [MW]

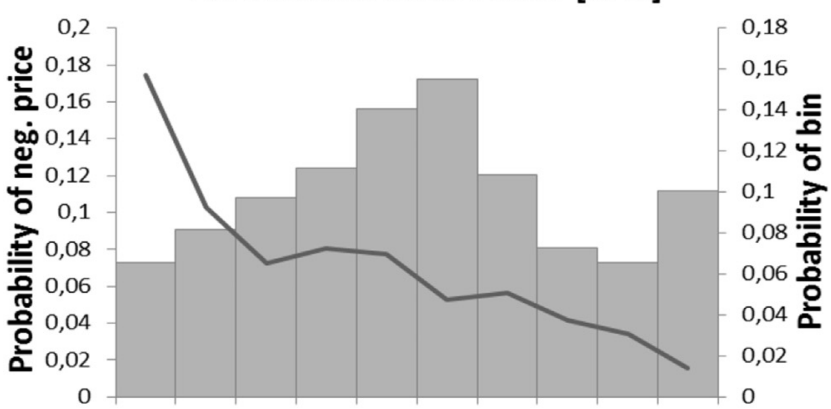

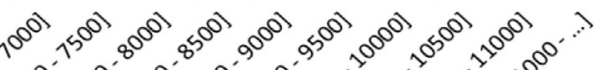

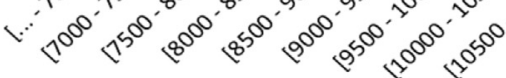

DA Forecast Load [MW]

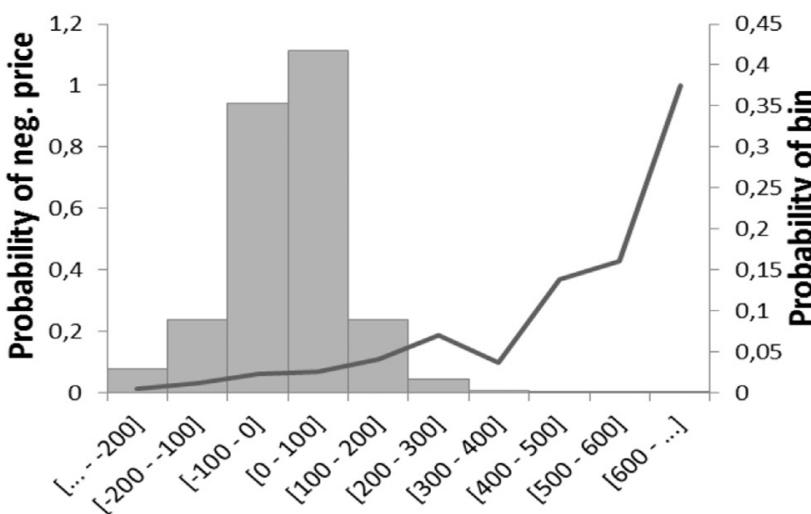

Wind Power Forecast Error [MW]

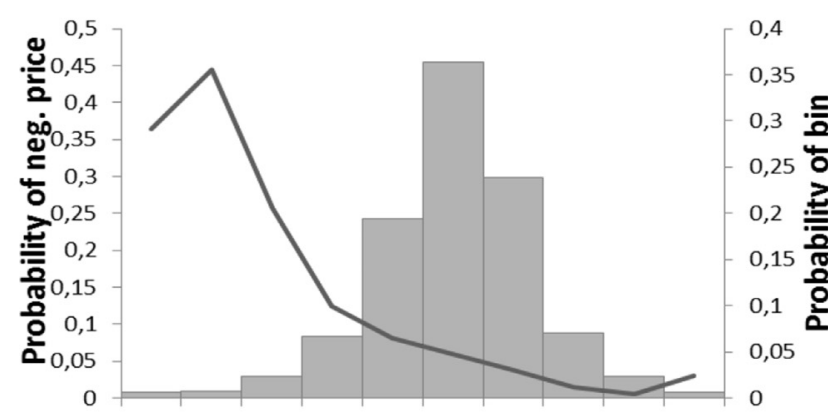

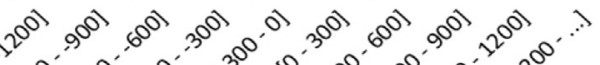

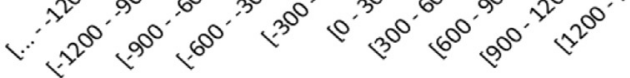
Load Forecast Error [MW]

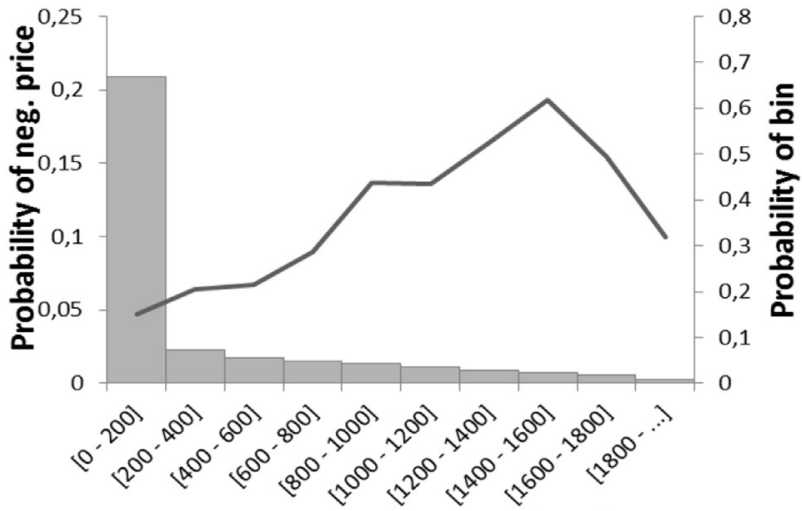

DA Forecast PV Power [MW]

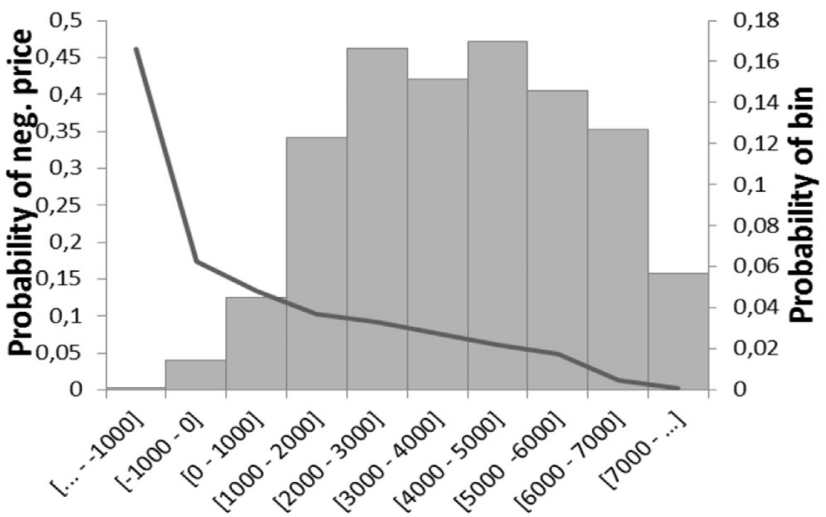

DA Forecast Net Load [MW]

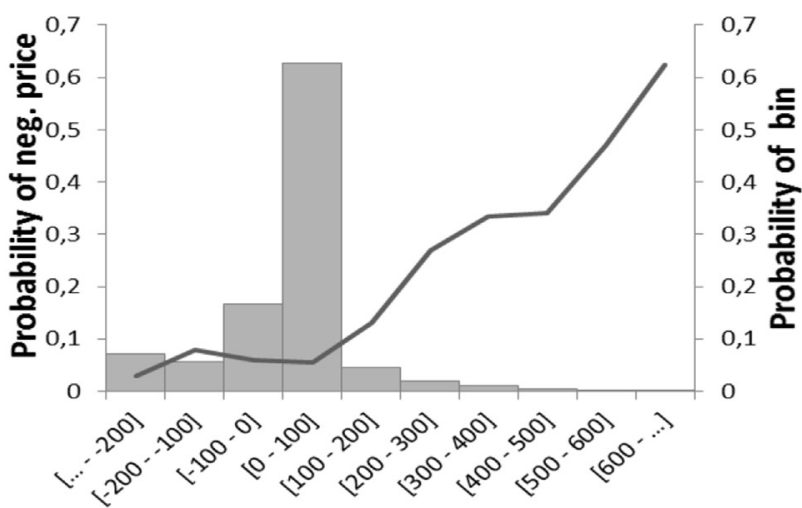

PV Power Forecast Error [MW]

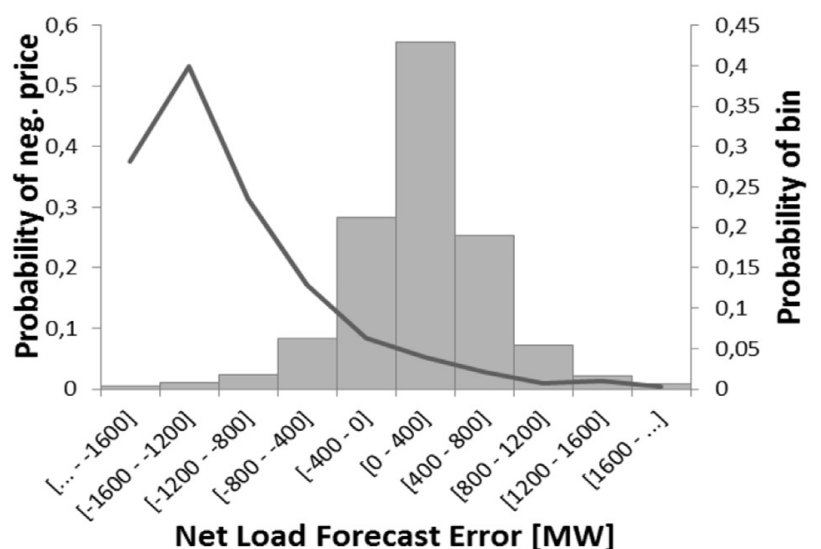

Net Load Forecast Error [MW]

Fig. 2. Probability of the occurrence of negative imbalance prices and probability of independent variables. 
error from load, wind power, and PV power. A positive net load forecast error represents a negative system imbalance and therefore a need for upward reserves. A negative net load forecast error means that there is a positive system imbalance and downward reserves need to be activated. Based on the observed values, negative prices have a higher probability to occur during periods experiencing more wind power than forecasted, more PV power than forecasted, less load than forecasted, and less net load than forecasted. For example, when looking at the load forecast error graph it can be noted that the lower the forecast error, the higher the probability of an imbalance price being negative (left axis), and it can also be noted that extreme load forecast errors only have a small probability to occur compared to moderate load forecast errors (right axis).

The previous observations identified potential negative and positive relationships between (i) predicted variations of renewables power generation and load, and negative imbalance prices on the one hand, and (ii) forecast errors of renewable power generation and load, and negative imbalance prices on the other hand. The flowchart shown in Fig. 3 shows those variables and illustrates their influence towards the imbalance price. However, two additional variables that were not analyzed - power plant outages and contracted reserves - also have to be taken into account but fall outside the scope of this article. On day-ahead the amount of available reserves and real-time flexibility is determined, as illustrated by the upper path in Fig. 3. The lower part of Fig. 3 illustrates how the volume of requested reserves and real-time flexibility is determined in real-time. First, it can be noted that the day-ahead forecasts determine the theoretical day-ahead predicted net load, and lowered by the scheduled inflexible base load units this determines the commitment and output of scheduled flexible base load, mid load, and peak load plants. The amount of scheduled conventional flexible power units and their scheduled power output consequently determines the available flexibility for the next day. Second, the forecast errors and power plant outages determine the BRPs' real-time imbalances, which aggregated form the system imbalance. The system imbalance determines the net regulated volume, representing the requested reserves and flexibility by the TSO. The interaction between available and requested reserve capacity consequently determines the imbalance price.
Based on the constructed flowchart displayed in Fig. 3, a negative imbalance price matrix is constructed and displayed in Fig. 4. It is illustrated that the combination of a high demand for downward reserves, resulting from forecast errors regarding renewable power generation, load, and power plant outages, with a low availability of cheap downward reserve capacity, resulting from the power plant scheduling based on day-ahead information, can lead to the occurrence of negative prices in the real-time balancing market.

\subsection{Regression analysis}

In this section the previously discussed observations and variables will be analyzed and tested through a series of linear regression analyses. The significance of the above stated variables is tested, including the presence of a positive or negative relation between the independent variables and the imbalance price, and the explanatory value of the individual independent variables is provided.

Each independent variable is found significant with at least $99 \%$ certainty, since their significance value is lower than 0.01 (Table 4). Aside from the significance value, Table 4 displays the regression equation (consisting of an intercept and a slope) and the R Square value for each of the tested independent variables. The regression coefficients, represented by the slope of the regression equation, display the change in the dependent variable-value (the Belgian imbalance price) when the independent variable rises with 1 unit. $R$ Square, also referred to as correlation coefficient, is the percentage of variance in the dependent variable that is explained by the independent variable. This is calculated as the correlation between the actual independent variable-values and the independent variable-values predicted by the regression model. This correlation coefficient proves to be the highest for the net load forecast error and the lowest for the day-ahead forecasted wind power.

The day-ahead forecasted wind power and PV power are negatively correlated with the imbalance price. The higher their values, the lower the day-ahead net load, which results in less scheduled conventional flexible power units and at lower run. This in turn means that there naturally is a low margin for downward regulation of these plants, i.e. little downward flexibility. Note that even if this flexibility is ensured by means of adequate contracted

DA forecast

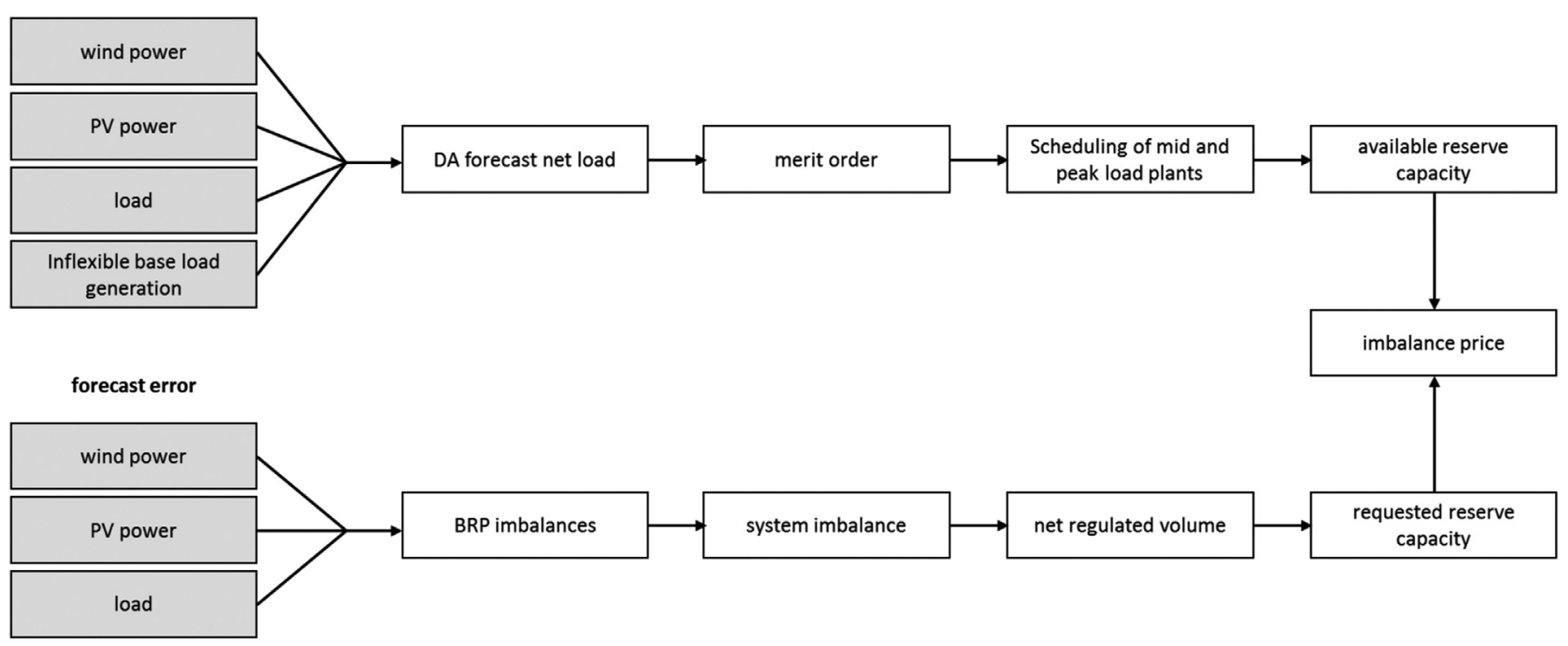

Fig. 3. Flowchart identifying potential imbalance price drives. 


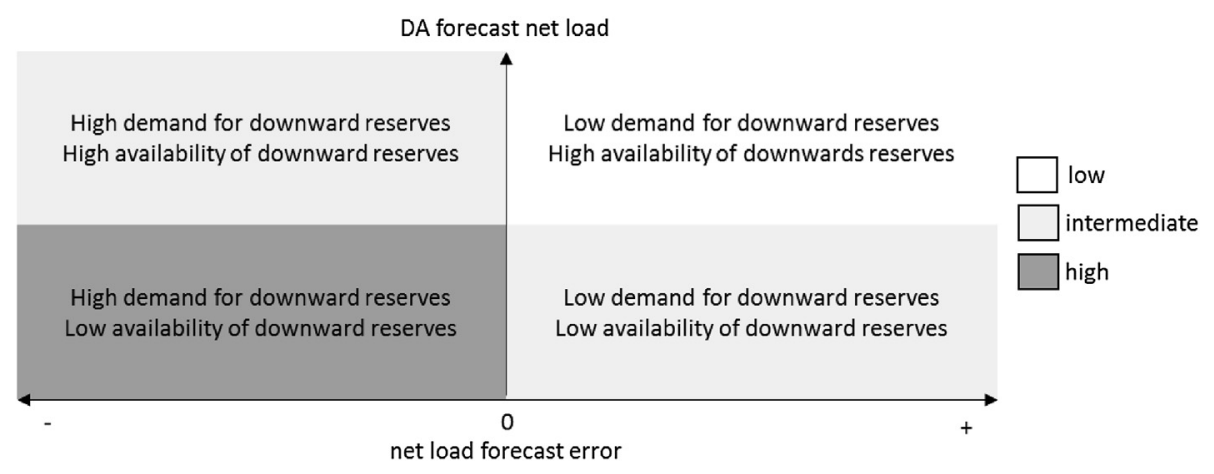

Fig. 4. Matrix illustrating the probability of negative imbalance prices.

reserve capacity, the downward activation will be expensive, i.e. low to negative prices, due to scarcity. In contrast to the scheduled renewable generation, the day-ahead forecasted load and net load is positively correlated with the imbalance price. The lower its value, the lower the day-ahead load and net load, again resulting in low-scheduled conventional power and consequently less or expensive flexibility for downward regulation.

Table 4 shows that the renewables forecast errors are negatively correlated with the imbalance price. If there is more renewable power than forecasted this generally results in a positive system imbalance, requiring downward reserve capacity to be activated. The load forecast error and net load forecast error are positively correlated with the imbalance price. If there is less load and less net load than forecasted, a positive system imbalance occurs leading to a need for downward reserve capacity. Typically, more requested downward reserve capacity results in a lower imbalance price, as they are selected according to a merit order of decreasing resulting imbalance prices.

\section{Discussion}

Negative imbalance prices are the result of a temporary discrepancy between the need and availability of real-time downward flexibility, i.e. downward reserve capacity. On the one hand, the need for real-time flexibility increases with the share of renewable generation. On the other hand, the availability of realtime flexibility decreases with the share of renewable generation as it replaces conventional generation, historically the main provider of balancing services. On the operational level, when expecting a low net load, conventional generators tend to operate at lower output levels, reducing the downward flexibility available. Large unexpected excess generation results in negative prices, which indicates the need for downward flexibility.

The occurrence of negative imbalance prices is thus a market signal reflecting scarcity of downward flexibility during periods with excess supply. It has to be taken into account that the

Table 4

Individual regression outcome for the identified independent variables.

\begin{tabular}{llrrrl}
\hline & Significant & Value & Intercept & Slope & R Square \\
\hline DA forecast wind power & Yes & 0.001 & 51.077 & -0.003 & 0.0003 \\
DA forecast PV power & Yes & 0.000 & 52.388 & -0.008 & 0.005 \\
DA forecast load & Yes & 0.000 & -54.828 & 0.012 & 0.083 \\
DA forecast net load & Yes & 0.000 & 19.129 & 0.008 & 0.077 \\
Wind power forecast error & Yes & 0.000 & 50.045 & -0.105 & 0.033 \\
PV power forecast error & Yes & 0.000 & 48.673 & -0.084 & 0.040 \\
load forecast error & Yes & 0.000 & 44.497 & 0.034 & 0.067 \\
net load forecast error & Yes & 0.000 & 43.586 & 0.036 & 0.100 \\
\hline
\end{tabular}

imbalance price is largely impacted by the market design. The calculation method can to a large extent affect the occurrence of negative imbalance prices. In average pricing systems negative imbalance prices can only occur in periods experiencing a weighted average price that is negative, which only occurs in extreme circumstances. Although average pricing results in less negative prices than marginal pricing, marginal pricing is believed to reflect the current market situation to all market participants to a better extent than average pricing. This leads to the observation that negative prices have to be viewed upon as market reflective.

These market signals provide an incentive for market participants to integrate new flexibility which is able to provide closeto-real-time downward power adjustments. In general, four categories of flexibility sources can be identified in electricity systems: flexible demand, flexible supply, storage capacity, grid capacity. With flexible supply downward adjustments are equivalent to a decrease in generation by reducing their fuel intake. We can expect that downward flexibility will also be provided by RES by means of curtailing their power output. However, currently RES generators have no incentive to curtail generation at excess supply periods as they receive a generationbased support, except for moments when facing extremely negative prices, thereby offsetting their received support. For flexible demand this implies an increase of consumption, for instance resulting from shifting consumption towards low or negative price periods. Electricity storage capacity is able to provide downward power adjustments by means of charging the storage system. Finally, the transmission grid is also a potential provider of downward power adjustments through exporting excess generation to neighboring regions.

\section{Conclusions}

This article investigates the occurrence of negative imbalance prices in Central Western Europe. After discussing the balancing market design, both an empirical and regression analysis is conducted on the parameters which are influencing the balancing market prices. It is found that on the one hand, the negative imbalance prices are substantially induced by the expected generation of wind and PV in low load periods, reducing the availability of downward flexibility necessary for downward regulation. This increases the activation price for downward reserve capacity, resulting in negative prices when facing high positive system imbalances. On the other hand, renewable generation and load prediction errors driving positive system imbalances contribute to the occurrence of negative imbalance prices through the need for expensive downward reserve activation in periods of scarce downward flexibility. 
It is concluded that the occurrence of these negative prices is not a problem as such, as they may provide correct short-term and long-term signals towards the need for flexibility, and facilitate their business case. These flexible technologies include electricity storage, demand response, interconnection capacity, and flexible generation. However, this price can be affected by the electricity market design such as renewable generation support mechanisms, or imbalance price calculation methods that are not cost reflective, thereby distorting the market price.

\section{References}

[1] ENTSO-E. Yearly statistics \& adequacy retrospect 2012 [Online]. Available from:. 2014. https://www.entsoe.eu/publications/statistics/yearly-statisticsand-adequacy-retrospect/Pages/default.aspx [accessed 21.03.14].

[2] ENTSO-E. Scenario outlook and adequacy forecast 2013-2030. 2013. Brussels.

[3] Bouffard F, Ortega-vazquez M. The value of operational flexibility in power systems with significant wind power generation. IEEE Power Energy Soc Gen Meet 2011:1-5.

[4] Ma J, Member S, Silva V, Belhomme R, Kirschen DS, Ochoa LF, et al. Evaluating and planning flexibility in sustainable power systems. IEEE Trans Sustain Energy 2013;4(1):200-9.

[5] IEA. Harnessing variable renewables - a guide to the balancing challenge. Paris: OECD; 2011

[6] Lannoye E, Flynn D, O'Malley M. Evaluation of power system flexibility. IEEE Trans Power Syst 2012;27(2):922-31.

[7] De Vos K. Sizing and allocation of operating reserves following wind power integration. KU Leuven; 2013.

[8] Eurelectric. Security of electricity supply - roles, responsibilities and experiences within the EU. 2006. Brussels.

[9] Finon D, Pignon V. Electricity and long-term capacity adequacy: the quest for regulatory mechanism compatible with electricity market. Util Policy Sep. 2008;16(3):143-58.

[10] KU Leuven Energy Institute. Negative electricity market prices. Leuven; 2014.

[11] Elia. Incompressibility: lack of system flexibility. 2012. Brussels.

[12] Genoese F, Genoese M, Wietschel M. Occurrence of negative prices on the German spot market for electricity and their influence on balancing power markets. In: 2010 7th International Conference on the European Energy Market; 2010. p. 1-6.

[13] Fanone E, Gamba A, Prokopczuk M. The case of negative day-ahead electricity prices. Energy Econ Jan. 2013;35(May 2008):22-34.

[14] Nicolosi M. Wind power integration and power system flexibility-An empirical analysis of extreme events in Germany under the new negative price regime. Energy Policy Nov. 2010;38(11):7257-68.

[15] Sewalt M, De Jong C. Negative prices in electricity markets. Commod Now 2003:74-7. June.

[16] Knittel C, Roberts M. An empirical examination of deregulated electricity prices. 2001. Berkeley, CA, USA.

[17] Paraschiv F, Erni D, Pietsch R. The impact of renewable energies on EEX dayahead electricity prices. Energy Policy, Oct. 2014;73:196-210.

[18] Azofra D, Jiménez E, Martínez E, Blanco J, Saenz-Díez JC. Wind power meritorder and feed-in-tariffs effect: a variability analysis of the Spanish electricity market. Energy Convers Manag Jul. 2014;83:19-27.

[19] Keles D, Genoese M, Möst D, Fichtner W. Comparison of extended meanreversion and time series models for electricity spot price simulation considering negative prices. Energy Econ Jul. 2012;34(4):1012-32.

[20] Cutler NJ, Boerema ND, MacGill IF, Outhred HR. High penetration wind generation impacts on spot prices in the Australian national electricity market. Energy Policy Oct. 2011;39(10):5939-49.

[21] Woo CK, Horowitz I, Moore J, Pacheco A. The impact of wind generation on the electricity spot-market price level and variance: the Texas experience. Energy Policy Jul. 2011;39(7):3939-44.

[22] Hiroux C, Saguan M. Large-scale wind power in European electricity markets: time for revisiting support schemes and market designs? Energy Policy Jul. 2010;38(7):3135-45.
[23] Vandezande L, Meeus L, Belmans R, Saguan M, Glachant J-M. Well-functioning balancing markets: a prerequisite for wind power integration. Energy Policy Jul. 2010;38(7):3146-54.

[24] van der Veen R, Abbasy A, Hakvoort R. Agent-based analysis of the impact of the imbalance pricing mechanism on market behavior in electricity balancing markets. Energy Econ Jul. 2012;34(4):874-81.

[25] CREG. Beslissing (B) 130704-CDC-1252 over het voorstel van de NV Elia System Operator betreffende de werkingsregels van de markt voor de compensatie van de kwartieronevenwichten - Gedeeltelijke inwerktreding op 1 oktober 2013 en volledige inwerktreding op 1 jan. 2013. Brussels.

[26] Barroso LA, Cavalcanti T, Giesbertz P, Purchala K. Classification of electricity market models worldwide. 2005.

[27] Ventosa M, Baıllo Á, Ramos A, Rivier M. Electricity market modeling trends. Energy Policy May 2005;33(7):897-913.

[28] Littlechild S. Electricity cash out arrangements. 2007.

[29] Ramos A, De Jonghe C, Six D, Belmans R. Demand response within current electricity wholesale market design. In: 13th European Conference of the International Association of Energy Economics; 2013.

[30] Elia. Available regulation capacity. 2014 [Online]. Available from: http://www. elia.be/en/grid-data/balancing/available-regulation-capacity [accessed 02.03.14].

[31] Elia. Product sheets: balance. [Online]. Available from: http://www.elia.be/en/ products-and-services/product-sheets. [accessed 05.04.14].

[32] Hirth L, Ziegenhagen I. Control power and variable renewables: a glimpse at German data. In: 10th International Conference on the European Energy Market; 2013. p. 10.

[33] Amprion. Balancing power settlement with balancing group managers. [Online]. Available from: http://www.amprion.net/en/control-area-balance. [accessed 02.03.14].

[34] TenneT. The imbalance pricing system as at 01-01-2001, revised per 26-102005. 2010.

[35] DNV KEMA. Description and structured comparison of current operating processes and products. 2013. Brussels.

[36] RTE. Imbalance settlement price. [Online]. Available from: http://clients.rtefrance.com/lang/an/visiteurs/vie/mecanisme/jour/prix.jsp. [accessed 12.04.14].

[37] CRE. Services système et mécanisme d'ajustement. [Online]. Available from: http://www.cre.fr/reseaux/reseaux-publics-d-electricite/services-systeme-etmecanisme-d-ajustement. [accessed 18.07.14].

[38] Lei M, Shiyan L, Chuanwen J, Hongling L, Yan Z. A review on the forecasting of wind speed and generated power. Renew Sustain Energy Rev May 2009;13(4):915-20.

[39] Santos-Alamillos FJ, Pozo-Vázquez D, Ruiz-Arias J a, Lara-Fanego V, TovarPescador J. A methodology for evaluating the spatial variability of wind energy resources: application to assess the potential contribution of wind energy to baseload power. Renew Energy Sep. 2014;69:147-56.

[40] De Vos K, Petoussis AG, Driesen J, Belmans R. Revision of reserve requirements following wind power integration in island power systems. Renew Energy Feb. 2013;50:268-79.

[41] De Vos K, Morbee J, Driesen J, Belmans R. Impact of wind power on sizing and allocation of reserve requirements. IET Renew Power Gener 2013:7(1):1-9.

[42] Brandstätt C, Brunekreeft G, Jahnke K. How to deal with negative power price spikes?-Flexible voluntary curtailment agreements for large-scale integration of wind. Energy Policy Jun. 2011;39(6):3732-40.

[43] Klinge Jacobsen H, Schröder ST. Curtailment of renewable generation: economic optimality and incentives. Energy Policy Oct. 2012;49:663-75.

[44] Elia. Data download page [Online]. Available from: http://www.elia.be/en/ grid-data/data-download; 2014 [accessed 25.02.14].

[45] TenneT. Export data. [Online]. Available from: http://www.tennet.org/english/ operational_management/export_data.aspx. [accessed 24.01.14].

[46] RTE. Balancing mechanism. [Online]. Available from: http://clients.rte-france. com/lang/an/visiteurs/vie/vie_mecanisme.jsp. [accessed 28.01.14].

[47] Aggarwal SK, Saini LM, Kumar A. Electricity price forecasting in deregulated markets: a review and evaluation. Int J Electr Power Energy Syst Jan. 2009;31(1):13-22.

[48] IBM. IBM SPSS software.

[49] Field A. Discovering statistics using IBM SPSS statistics. 4th ed. London: SAGE Publications Ltd; 2013. 